\title{
Electrostatically-coupled graphene oxide nanocomposite cation exchange membrane
}

\author{
Adetunji Alabi ${ }^{\mathrm{a}}$, Levente Cseri ${ }^{\mathrm{b}}$, Ahmed Al Hajaj ${ }^{\mathrm{c}}$, Gyorgy Szekely ${ }^{\mathrm{b}, \mathrm{d}}$, Peter Budd ${ }^{\mathrm{e}}$, Linda Zou ${ }^{\mathrm{a}, *}$

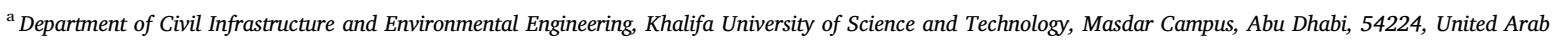 \\ Emirates \\ ${ }^{\mathrm{b}}$ School of Chemical Engineering and Analytical Science, University of Manchester, The Mill, Sackville Street, Manchester, M1 3BB, United Kingdom \\ ${ }^{\mathrm{c}}$ Department of Chemical Engineering, Khalifa University of Science and Technology, Masdar Campus, Abu Dhabi, 54224, United Arab Emirates \\ ${ }^{\mathrm{d}}$ Advanced Membranes \& Porous Materials Center, Physical Science Engineering Division (PSE), King Abdullah University of Science and Technology (KAUST), Thuwal, \\ 23955-6900, Saudi Arabia \\ ${ }^{\mathrm{e}}$ School of Chemistry, University of Manchester, Oxford Road, Manchester, M13 9PL, United Kingdom
}

\section{A R T I C L E I N F O}

\section{Keywords:}

Graphene oxide

Cation exchange membrane

Nanocomposite

Electromembrane desalination

L-DOPA

poly(sodium 4-styrenesulfonate)

\begin{abstract}
A B S T R A C T
We report the preparation of an electrostatically-coupled graphene oxide nanocomposite cation exchange membrane (CEM) based on sulfonic group containing graphene oxide (SGO) (45 wt \% loading) and polyvinylidene fluoride (PVDF), where the ion exchange groups were provided by the SGO additive. SGO was prepared via the mixing of graphene oxide (GO) with a mixture derived from 3,4-dihydroxy-L-phenylalanine (LDOPA) and poly(sodium 4-styrenesulfonate) (PSS). A mold-casting technique was developed to fabricate the free-standing nanocomposite CEM. The presence of sulfonic groups in the nanocomposite was confirmed with FTIR spectroscopy. Energy dispersive spectroscopy analysis showed the SGO was distributed across the entire membrane matrix, with minimal aggregation. The resultant SGO/PVDF nanocomposite CEM membrane demonstrated high hydrophilicity and high water uptake, but low swelling ratio. Furthermore, evaluation of the electrochemical properties of the nanocomposite CEM showed favorable ion exchange capacity $(0.63 \pm 0.08$ meq $/ \mathrm{g})$, permselectivity $(0.95 \pm 0.04)$, and area resistance $\left(2.8 \pm 0.2 \Omega \mathrm{cm}^{2}\right)$. The nanocomposite CEM show good potential for use in electromembrane desalination applications.
\end{abstract}

\section{Introduction}

In view of recent trends, i.e. the depletion rate of fresh water resources, growing global population and climate change, there is a serious need to address not only our water demands for today, but also for the future [1]. The importance of sufficient fresh water supply cannot be overstated. As a result, desalination technologies such as electromembrane desalination have been developed to safeguard water security. Electromembrane desalination, which includes electrodialysis [2-8] and membrane capacitive deionization [9-13], uses ion exchange membranes (IEMs) to produce fresh water from brackish water. IEMs are membranes with charged groups which attract counter-ions and repel co-ions from ionic solutions. IEMs which conduct anions are termed anion exchange membranes (AEMs), while those which conduct cations are termed cation exchange membranes (CEMs) [6,14-16].

To be effective, IEMs are required to possess high ion exchange capacity (IEC), high permselectivity and high ionic conductivity, as well as chemical stability [17]. Strategies to enhance the properties of IEMs have been investigated in order to increase the separation efficiency and reduce the energy consumption of electromembrane desalination processes. The polymeric ion exchange membranes can be classified into homogeneous and heterogeneous according to the way the ion exchange groups are incorporated [18]. For homogeneous IEMs, the ion exchange groups are attached directly to the polymer backbone; these membranes are considered chemically more stable. Heterogeneous IEMs have a more disperse distribution of ion exchange sites that are independent from the polymeric structure. They have the advantages that their ion exchange properties can be tuned by varying the loading of the ion exchange additive particles and that they have lower production costs than their homogeneous counterparts. With the advancement of interfacial science and nanotechnology, more versatile approaches are needed for incorporating ion exchange functional groups into heterogeneous IEMs. The use of nanomaterials as non-ion exchange additives is a known strategy. Nanocomposite IEMs, developed by incorporating additives into polymeric membrane matrices, have demonstrated considerable improvements, particularly in

\footnotetext{
* Corresponding author.

E-mail address: linda.zou@ku.ac.ae (L. Zou).
} 
mechanical strength and other properties, in comparison to their homogeneous counterparts [19]. Typical additives include carbon nanotubes [20], silica [21], and graphene-based nanomaterials [22]. High additive loadings tend to result in nanocomposite IEMs with reduced ion exchange capacity [19]. This may, however, be resolved by functionalizing the additives with charged species to provide additional ion exchange groups. In addition, additives can also be functionalized to improve their dispersibility [19].

There has been immense interest in the use of graphene-based nanomaterials as additives in nanocomposite membranes [23-27]. Graphene oxide (GO), a two dimensional (2D) material, has been commonly used in developing nanocomposite membranes for membranebased applications [23,28,29]. Properties such as high surface area, high mechanical stability and high thermal stability make GO a suitable additive option for nanocomposite membranes. In addition, GO can be easily dispersed in many of the solvents typically used in membrane casting [30]. It is therefore rational that GO-based nanomaterials have received attention as additives for nanocomposite IEMs. Typically, the GO-based additive content of IEMs is in the range of 0.5 to $15 \mathrm{wt} \%$ [19].

A major challenge with nanocomposite membranes is that they tend to become less stable with high additive loadings [31]. This is due to poor additive dispersion, which leads to agglomeration of additives in the polymer matrix $[32,33]$. Added-nanomaterial agglomeration results in the formation of failure sites within nanocomposite membranes $[26,31,32,34]$, hindering practical applications. GO has been reported as an additive bearing ion exchange groups to improve the conductivity of the membranes [19]. However, there are issues associated with GO in ion exchange membranes: (1) GO's stability and its function will deteriorate as it is very hydrophilic and will take up water and swell easily [35]; and (2) there are limited sites available on GO for chemical functionalization with ion exchange groups, so the IEC is low. In our previous attempt, GO was modified using sulfanilic acid as the sulfonating agent. The resultant sulfonated GO was then used as an ion exchange additive by incorporation in an inert PVDF polymer matrix. It was found that the IEC measurements were too low, and thus led to the conclusion that it is difficult to achieve the desired degree of sulfonation due to the inadequate amount of sites on GO for chemical functionalization. In order to achieve high IEC with this strategy, an approach is necessary that allows higher loading of ion exchange additives, so the density of the ion exchange groups in the membrane can be increased.

The nanocomposite IEMs found in literature derived most or all of their ion exchange capabilities from sources other than nanomaterial additives [19]. In these reported cases, most or all of the ion exchange properties were provided by: (1) polymers with charged groups (prepared by chemically modifying the polymers at the pre-membrane casting stage [36-38] or post-membrane casting stage [39-41]); or (2) ion exchange resins [42-44]. We propose a different option for nanocomposite IEMs development, wherein all the ion exchange groups are provided by the nanomaterial additive. This offers more flexibility in terms of materials selection and combinations.

In this work, we propose a concept of electrostatically-coupled PSS/ L-DOPA/GO (SGO) as a cation-exchange additive for polymeric (PVDF) membranes (Fig. 1), and report: (1) a procedure for preparing sulfonic group containing graphene oxide nanocomposite additive (SGO) (Fig. 2); and (2) a mold-casting technique used to fabricate PVDF-based nanocomposite CEMs with a high SGO loading of $45 \mathrm{wt} \%$ (Fig. 3) to provide ion exchange properties in the membrane. We have not found any previous report of the successful fabrication of nanocomposite IEMs in which all the ion exchange groups are provided by ionic conducting nanomaterials. PVDF is a known polymer that is chemically stable and forms membranes with controllable porosity. In order to introduce a sufficient quantity of ion exchange groups, the loadings of the SGO have been trialed to achieve as high loading as possible; it was found that up to $45 \mathrm{wt} \%$ is the practically maximum loading, to maintain the mechanical integrity of the composite membrane. The SGO was synthesized via the functionalization of GO by coating with a mixture of 3,4-dihydroxy-L-phenylalanine (L-DOPA) and poly(sodium 4-styrenesulfonate) (PSS). L-DOPA can strongly adhere to surfaces by virtue of its catechol groups [45-48]. L-DOPA is a natural amino acid found in proteins secreted by marine mussels for strong attachment on wet surfaces. As reported in the literature, polydopamine forms strong covalent and non-covalent adhesion with the surface of various materials, such as polystyrene (PS), poly(vinylidenefluoride) (PVDF), graphene oxide (GO) and many more [49]. The current theory of the polymerization mechanism of dopamine involves auto-oxidation and leads to the formation of dopamine-quinone and 5,6-dihydroxiyindole [50]. In a similar way to dopamine, L-DOPA polymerizes to form poly (L-DOPA) [51]. The poly(L-DOPA) can interact with PSS via physical co-adsorption to form an adsorbed layer. Polystyrene sulfonates (PSS) are commercially available water-soluble cation exchange polymers with high sulfonate content. L-DOPA can form non-covalent bonds with PSS as well as with the GO sheets and allow their subsequent immobilization to a polymer substrate. L-DOPA is the key part of the concept; without it the concept cannot be realized. Since GO has abundant functional groups and is very hydrophilic, in an aqueous environment GO will easily adsorb water and swell [35]; this causes an adverse effect on its function as a sustainable membrane material. Similarly, PSS is highly soluble in water and may leach out. Hence, LDOPA was employed as an electrostatic coupler between GO and PSS to prepare SGO. The influence of the SGO additive on the physico- and electrochemical properties of the nanocomposite CEM was investigated.

\section{Experimental}

\subsection{Materials}

Ethanol (96\% v/v) was bought from Honeywell (USA). Graphite flakes were obtained from Bay Carbon Limited (USA). Tris(hydroxymethyl)aminomethane (99.8\%), sulfuric acid $\left(\mathrm{H}_{2} \mathrm{SO}_{4} ; 95.0-97.0 \%\right)$, potassium permanganate $\left(\mathrm{KMnO}_{4} ; 99-100.5 \%\right)$, sodium nitrite $\left(\mathrm{NaNO}_{2}\right.$; 97.0\%), hydrogen peroxide $\left(\mathrm{H}_{2} \mathrm{O}_{2} ; 34.5-36.5 \%\right)$, hydrochloric acid ( $\mathrm{HCl} ; 37 \%)$, sodium hydroxide $(\mathrm{NaOH}$; $98-100.5 \%)$, potassium chloride (KCl; 99.0-100.5\%), poly(vinylidene fluoride) (PVDF; weight-average molecular weight $M_{\tilde{\mathrm{w}}} 180,000$, number-average molecular weight $M_{\tilde{\text { ñ }}}$ 71,000 by gel permeation chromatography), $N$-methyl-2-pyrrolidone (NMP; 99.5\%), 3,4-dihydroxy-L-phenylalanine (L-DOPA; 98\%), and poly(sodium 4-styrenesulfonate) (PSS; $M_{\mathrm{w}^{\sim}} 70,000,30 \mathrm{wt} \%$ in $\mathrm{H}_{2} \mathrm{O}$ ) were obtained from Sigma Aldrich. DI water was used all through the experiments.

\subsection{Preparation of PSS/L-DOPA coupled GO (SGO)}

Graphite oxide was firstly synthesized from graphite powder by the modified Hummers' method [23,52]. According to literature, this Hummers' method followed by exfoliation mainly produces monolayers with a flake size of $0.5-1.0 \mu \mathrm{m}[53,54] .120 \mathrm{~mL}$ of concentrated $\mathrm{H}_{2} \mathrm{SO}_{4}$ was cooled in an ice bath for $40-45 \mathrm{~min}$. Then $1 \mathrm{~g}$ of graphite powder and $0.5 \mathrm{~g}$ of $\mathrm{NaNO}_{2}$ were added to the chilled concentrated $\mathrm{H}_{2} \mathrm{SO}_{4}$ and stirred for $15 \mathrm{~min}$. The solution was black in color. To this mixture, $6 \mathrm{~g}$ of $\mathrm{KMnO}_{4}$ was slowly added, after which the solution was stirred for $45 \mathrm{~min}$. The color of the solution became dark green. The solution was then placed in a water bath with continuous stirring and heating at $35^{\circ} \mathrm{C}$ for $2 \mathrm{~h}$. Then the solution was placed in an ice bath followed by slow addition of $125 \mathrm{~mL}$ DI water. The color of the solution changed from dark green to dark brown. Afterwards, the solution was taken out of the ice bath and stirred continuously at room temperature. Then $250 \mathrm{~mL}$ DI water was added followed by dropwise addition of $\mathrm{H}_{2} \mathrm{O}_{2}$ till the solution turned golden yellow in color. The solution was then filtered to recover graphite oxide mud. The mud was washed with $200 \mathrm{~mL}$ dilute $\mathrm{HCl}$ solution (1:10 by volume), twice, and then with $250 \mathrm{~mL}$ DI 

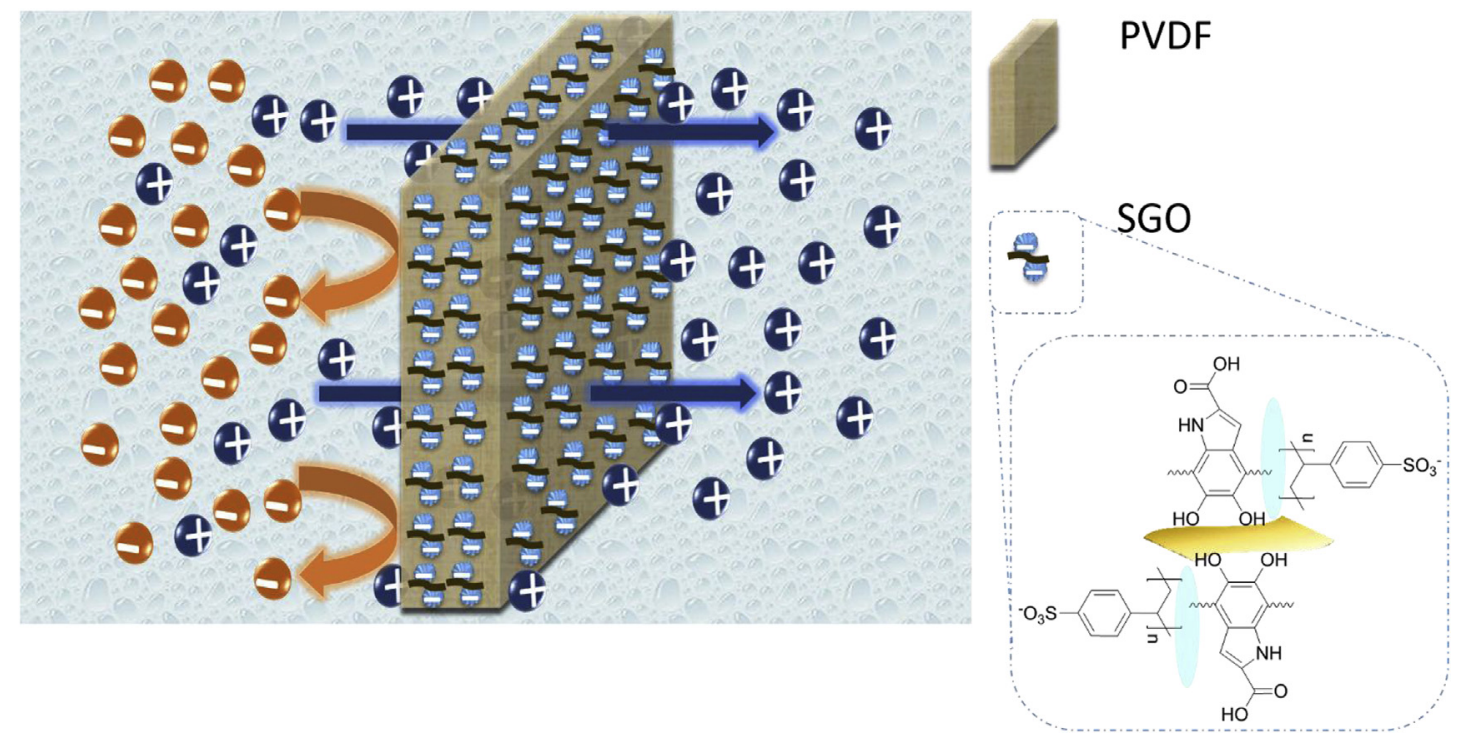

Fig. 1. The concept of electrostatically-coupled PSS/L-DOPA/GO (SGO) as a cation-exchange additive in a polymeric (PVDF) membrane.

water, twice. At this point, the mud became dark brown in color. The graphite oxide paste was then added to $250 \mathrm{~mL}$ of DI water, then stored in a refrigerator for later use. The concentration of the graphite oxide solution was ca. $8 \mathrm{~g} / \mathrm{L}$.

A stock buffer solution was then prepared by dissolving $12.1 \mathrm{~g}$ of Tris in $200 \mathrm{~mL}$ of DI water at room temperature, followed by dropwise addition of $1 \mathrm{M} \mathrm{HCl}$ to adjust the $\mathrm{pH}$ to 8.3 . This buffer solution was stored for later use. Then $0.75 \mathrm{~mL}$ of the stock buffer solution was diluted to $750 \mathrm{~mL}$ by addition of DI water. Next, $1.5 \mathrm{~g}$ of L-DOPA was added and stirred for $30 \mathrm{~min}$ at room temperature. Then $15 \mathrm{~mL}$ PSS was added and stirring was continued for $4 \mathrm{~h}$ at room temperature. The solution became black in color. $150 \mathrm{~mL}$ of graphite oxide solution was added and the solution was stirred for $3 \mathrm{~h}$. The solution was filtered with a vacuum filtration setup and the mud was recovered. The mud was washed with DI water and ethanol to remove excess reagents. The mud was added to $35 \mathrm{~mL}$ of NMP and placed in an ice bath. A probe ultrasonicator was then used to exfoliate the mud to produce SGO dispersion. The exfoliation was performed in an ice bath to prevent the heating of the SGO/NMP dispersion. The concentration of the SGO/ NMP dispersion was $34 \mathrm{mg} / \mathrm{mL}$ of NMP. The proposed reaction scheme is shown in Fig. 2.<smiles>N[C@@H](Cc1ccc(O)c(O)c1)C(=O)O</smiles><smiles>C[13CH][13CH][13CH]</smiles>

5,6 dihydroxyindole-2-carboxylic acid<smiles>O=C(O)c1cc2cc(O)c(O)cc2[nH]1</smiles><smiles>CC[Pb]CO[Pb]</smiles>

Ad-layer formation

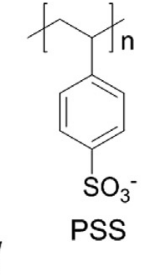

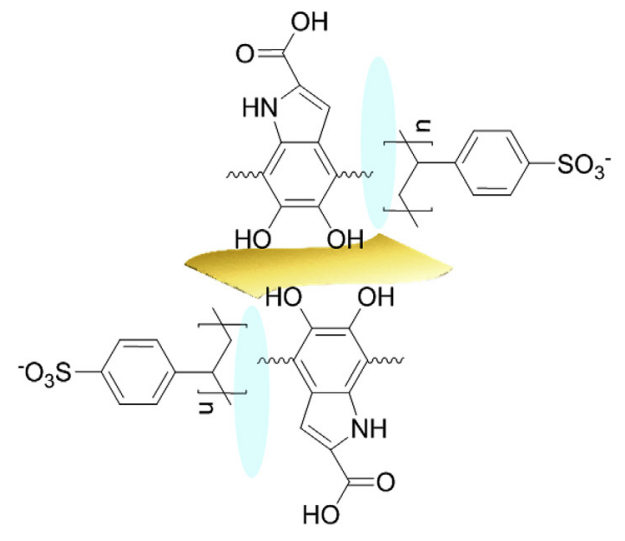

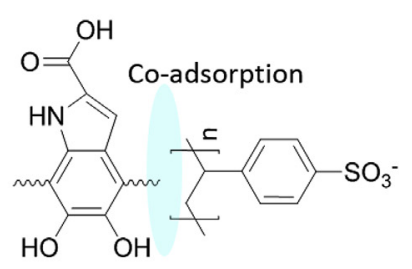

\section{SGO}

Fig. 2. Schematic illustration of the proposed assembly of cation exchange groups to produce SGO. 


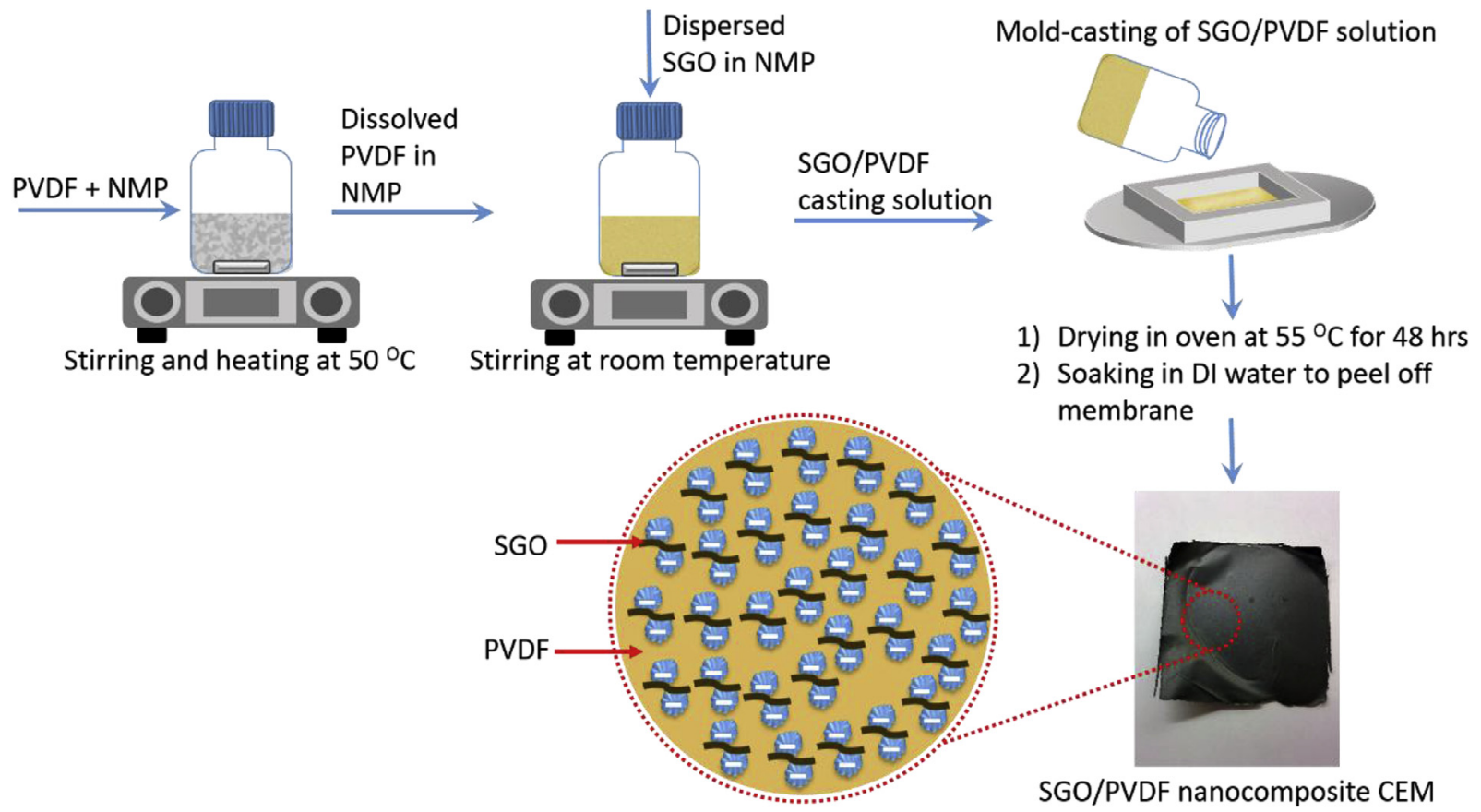

Fig. 3. Schematic depiction of the fabrication of SGO/PVDF nanocomposite membrane.

a)

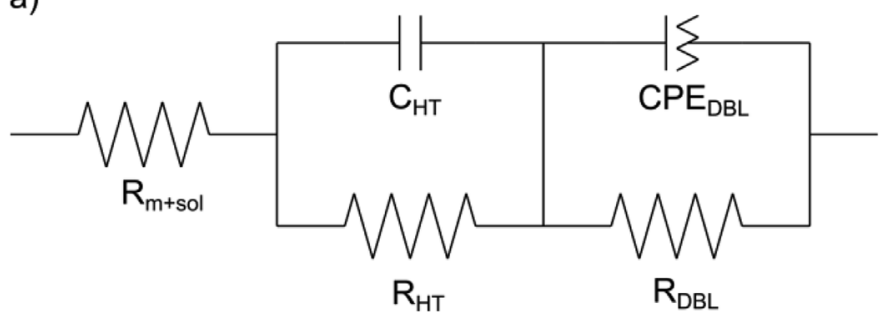

\subsection{Fabrication of membranes}

The SGO/PVDF nanocomposite membrane was fabricated according to the following steps (Fig. 3). $1.5 \mathrm{~g}$ of PVDF was added to $10 \mathrm{~mL}$ NMP and stirred at $60{ }^{\circ} \mathrm{C}$ for $1 \mathrm{~h}$ to dissolve the PVDF, then stirred again at room temperature for $10 \mathrm{~min}$. The casting solution was colorless at this stage. All of the SGO dispersion (from above) was added to the solution and stirred at room temperature for $2 \mathrm{~h}$ to obtain a uniform black-colored casting solution. The final composition of the casting solution was $1.2 \mathrm{~g}$ SGO: $1.5 \mathrm{~g}$ PVDF: $45 \mathrm{~mL}$ NMP. For each SGO/PVDF membrane obtained, $4 \mathrm{~mL}$ of the casting solution was poured into a square mold (7 cm internal length) with a 7-inch silica wafer at the base. By controlling the volume of the casting solution poured into the mold, the membrane thickness could be controlled. The mold-cast sample was then placed in an oven at $55^{\circ} \mathrm{C}$ for 3 days to evaporate the solvent. Then the silica wafer was immersed in DI water to peel off the SGO/PVDF membrane.

Plain PVDF membranes were also fabricated according to the procedure described above, but without the addition of SGO dispersion. Plain PVDF was used as benchmark to demonstrate the impact of adding SGO on the membrane structure, such as packing density, membrane morphology, wettability and swelling ratio.

\subsection{Characterization}

FTIR characterization was performed with an Attenuated Total Reflectance (ATR) in transmittance mode. The equipment manufacturer and model is Bruker Vertex 80v. The ATR was a platinum ATR b)

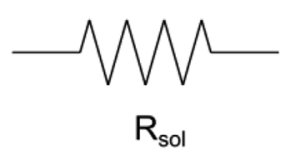

Fig. 4. Equivalent circuits used to model a) the CEM immersed in solution and b) the empty cell [58]. $R_{m+s o l}$ is the resistance of the membrane and the solution; $\mathrm{C}_{\mathrm{HT}}$ and $\mathrm{R}_{\mathrm{HT}}$ are the capacitance and resistance arising from the heterogeneous ionic transport, $\mathrm{CPE}_{\mathrm{DBL}}$ and $\mathrm{R}_{\mathrm{DBL}}$ is the constant phase element and resistance representing the diffusion boundary layer; while $\mathrm{R}_{\mathrm{sol}}$ is the resistance of the solution.
Diamond, Type A225/Q. The software used for analysis was OPUS 7.0. Configurations used were resolution of $4 \mathrm{~cm}^{-1}$, sample scan time of 64 scans, and background scan time of 64 scans. The spectra were recorded from 2000 to $400 \mathrm{~cm}^{-1}$. Raman spectroscopy was performed using Witec Alpha 300 RAS. The excitation wavelength was $532 \mathrm{~nm}$.

The morphology of the surface and cross-section of the membrane samples was studied using a FEI ${ }^{\mathrm{TM}}$ Nova NanoSEM 650. All samples were coated with $\mathrm{Au} / \mathrm{Pd}$ before the analysis. For the cross-section, the membranes were dipped in liquid nitrogen before snapping. The thickness of the membranes was determined using ImageJ software. The topography of the synthesized membranes was analyzed using an Asylum Research Cypher Atomic Force Microscope in tapping mode. The root mean square (RMS) roughness was determined using the Asylum Research software. FEI Quanta 3D FEG and TEAM ${ }^{\mathrm{TM}}$ EDS software were used to perform elemental analysis and mapping of the membrane samples.

Water contact angle measurements were performed using EasyDrop KRUSS. For each measurement, the volume of droplet dosed on the membrane samples was $10 \mu \mathrm{L}$. The average of five measurements was selected as the final value. Water uptake and swelling ratio measurements were carried out for the membrane samples. The membranes were soaked in DI water for $12 \mathrm{~h}$, then the weights and lengths of the wet samples were obtained. The wet samples were then dried in an oven at $50^{\circ} \mathrm{C}$ for $12 \mathrm{~h}$. Afterwards, the weights and lengths of the dried samples were measured. The water uptake and swelling ratio were calculated thus: 

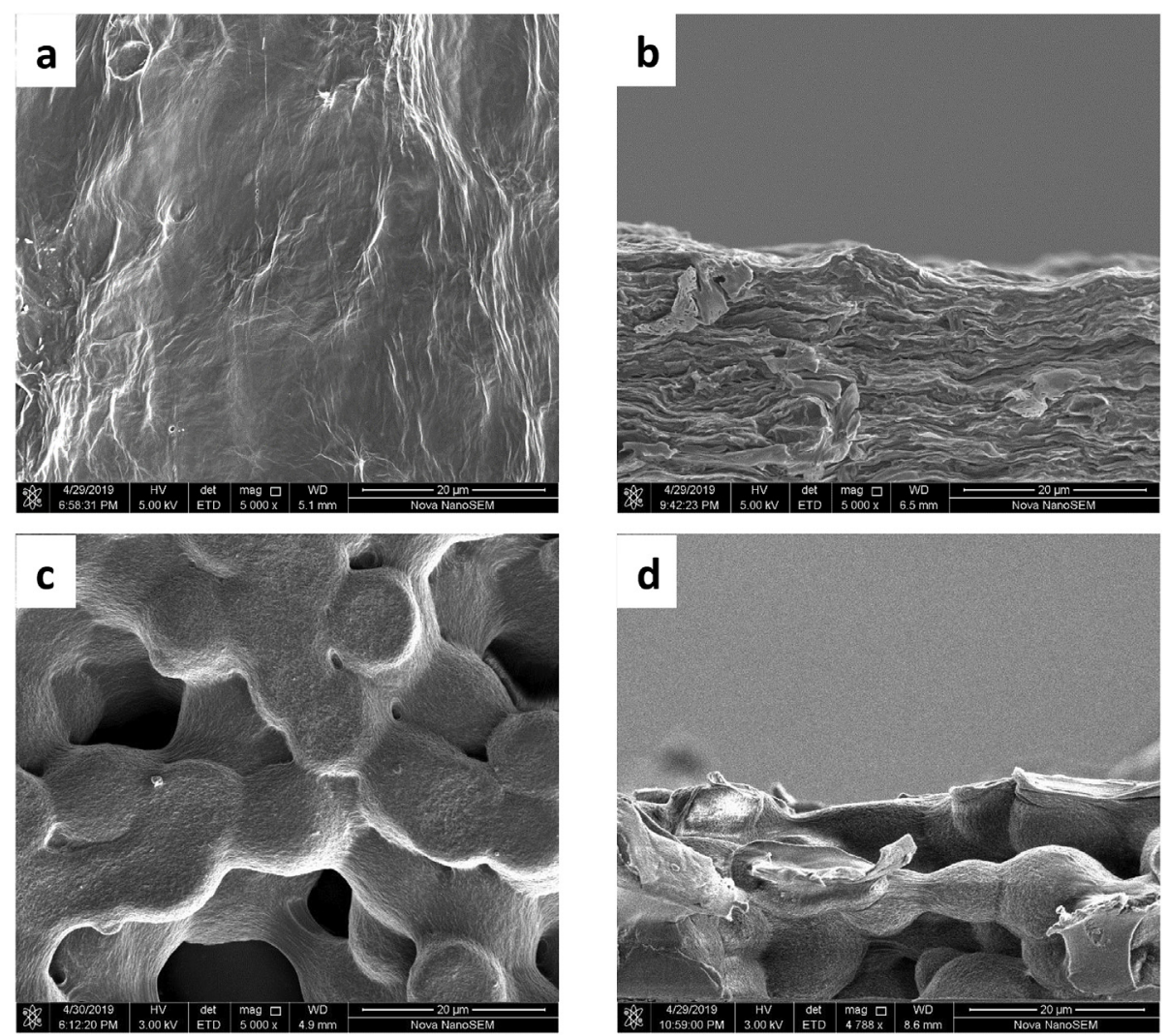

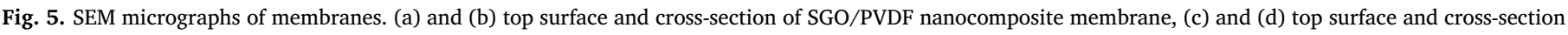
of PVDF membrane.

Water uptake $=\frac{m_{w e t}-m_{d r y}}{m_{d r y}} \times 100 \%$

where $m_{\text {wet }}$ is the weight of the wet membrane and $m_{\text {dry }}$ is the weight of the dry membrane.

Swelling ratio $=\frac{L_{w e t}-L_{d r y}}{L_{d r y}} \times 100 \%$

where $L_{w e t}$ is the length of the wet membrane and $L_{d r y}$ is the length of the dry membrane.

Ion exchange capacity of the membranes was evaluated by the classical acid-base titration method [16,55]. Membrane pieces of known weights were soaked in $50 \mathrm{~mL} 1 \mathrm{M} \mathrm{HCl}$ for $24 \mathrm{~h}$, to convert the membrane into $\mathrm{H}^{+}$form. The membranes were washed thoroughly to remove any trace of $\mathrm{HCl}$ (the wash water was tested with $\mathrm{AgNO}_{3}$ for the presence of $\mathrm{AgCl}$ precipitate). The membranes were then soaked in $50 \mathrm{~mL} 1 \mathrm{M} \mathrm{NaCl}$ for $24 \mathrm{~h}$ to displace the $\mathrm{H}^{+}$ions with $\mathrm{Na}^{+}$. Then the membrane-soaked solution was titrated against $0.01 \mathrm{M} \mathrm{NaOH}$ (using phenolphthalein as indicator) to determine the concentration of $\mathrm{H}^{+}$ ions. The IEC was then determined according to Eq. (3):

$\mathrm{IEC}=\frac{V_{\mathrm{NaOH}} C_{\mathrm{NaOH}}}{m_{d r y}}$

where $V_{\mathrm{NaOH}}$ is the volume of $\mathrm{NaOH}$ solution consumed in the titration, $C_{\mathrm{NaOH}}$ is the molar concentration of the $\mathrm{NaOH}$ used in the titration, and $m_{\mathrm{dry}}$ is the mass of the dry membrane.

The permselectivity of an IEM can be described as the charge selectivity of the IEM i.e. the preferential passage of counter ions through the IEM. It is measured by the amount of co- and counter ions in the IEM, and is dependent primarily on the IEC of the IEM and the concentration of ions in the solution. An ideal IEM would be permeable to its counter ions only, and thus have a permselectivity of 1 . The permselectivity value was obtained from chronopotentiometry measurements as reported earlier [22]. The sodium form of the CEM was conditioned by immersion in $0.1 \mathrm{M} \mathrm{NaCl}$ for $24 \mathrm{~h}$ before the measurements. A plastic sandwich with a round exposed area of $0.264 \mathrm{~cm}^{2}$ was used to hold the membrane in place. $\mathrm{Ag} / \mathrm{AgCl}$ electrodes were employed as reference and sensing electrodes, whereas platinum mesh electrodes were employed as working and counter electrodes. The compartments of the test cell were each filled with $50 \mathrm{~mL} 0.1 \mathrm{M} \mathrm{NaCl}$, with continuous stirring of the solution during the measurements. A PGSTAT302 N potentiostat/galvanostat (Metronohm Autolab, Netherlands), in galvanostatic mode at $8 \mathrm{~mA}$, was used to generate the chronopotentiometric curves. The software used for the analysis was Nova1.11. The transition time was obtained at the point of inflection of the chronopotentiometric curves. The permselectivity was determined using the modified Sand equation (Eq. (4)) [56]:

$P=\frac{|z| \cdot F \cdot D^{0.5} \cdot \pi^{0.5} \cdot C}{2\left(1-t_{\mathrm{i}}\right) \cdot \frac{I}{A} \cdot \tau^{0.5}}$

where $P$ is the permselectivity, $|\mathrm{z}|$ is the absolute charge of the sodium ion $(|+1|), F$ is the Faraday constant $\left(96,485 \mathrm{~A} \mathrm{~s} \mathrm{~mol}^{-1}\right), D$ is the diffusion coefficient $\left(1.48 \times 10^{-5} \mathrm{~cm}^{-2} \mathrm{~s}^{-1}\right)$ and $t_{\mathrm{i}}$ is the transport number (0.396) of the sodium ion in $0.1 \mathrm{M} \mathrm{NaCl}$ [56], $C$ is the concentration of the sodium ions ( $0.1 \mathrm{M}), I$ is the applied current $(8 \mathrm{~mA}), A$ is the exposed membrane area $\left(0.264 \mathrm{~cm}^{2}\right)$, and $\tau$ is the transition time. The final value was obtained as an average of a total of nine measurements on three independent membrane pieces.

The membrane area resistance was determined by electrochemical impedance spectroscopy (EIS) using a similar setup to the chronopotentiometry measurements. The compartments of the test cell were each filled with $50 \mathrm{~mL} 1.0 \mathrm{M} \mathrm{NaCl}$ and there was no stirring of the solution during the measurements. The membrane was conditioned by immersion in $1.0 \mathrm{M} \mathrm{NaCl}$ for $24 \mathrm{~h}$ before the measurements. A PGSTAT302 N, a potentiostat/galvanostat with FRA32 M frequency 

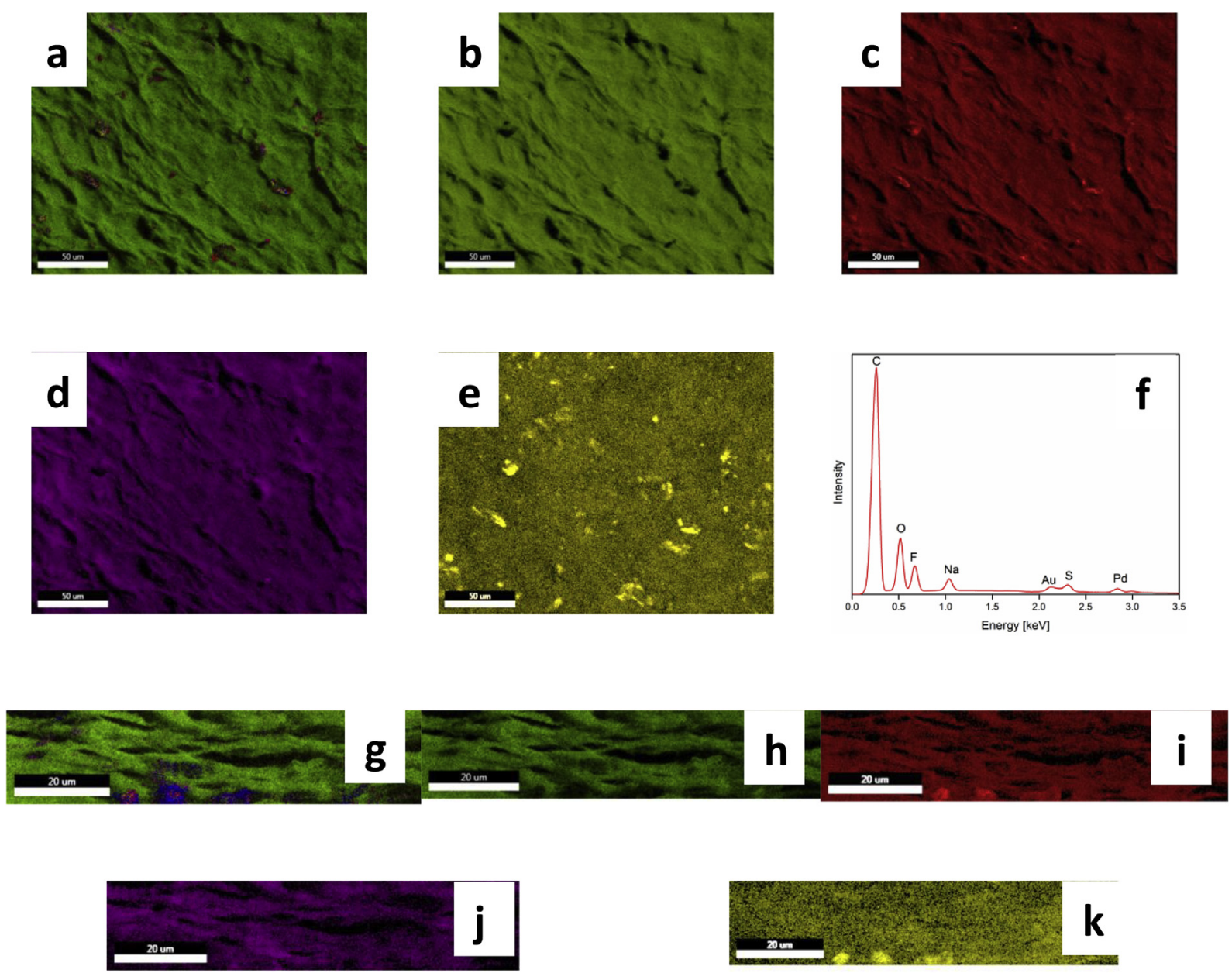

Fig. 6. EDS analysis of SGO/PVDF nanocomposite membrane: (a) composite map of top surface; (b) carbon map of top surface; (c) oxygen map of top surface; (d) fluorine map of top surface; (e) sulfur map of top surface; (f) EDS spectra of top surface; (g) composite map of cross-section; (h) carbon map of cross-section; (i) oxygen map of cross-section; (j) fluorine map of cross-section; (k) sulfur map of cross-section.

a

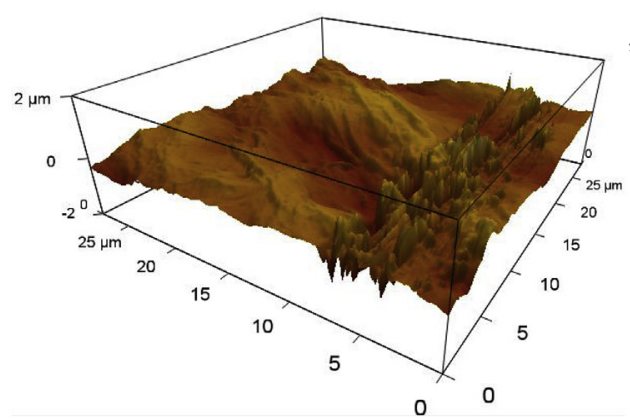

C

$$
\Theta=80.8 \pm 1.5^{\circ}
$$

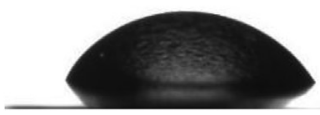

b

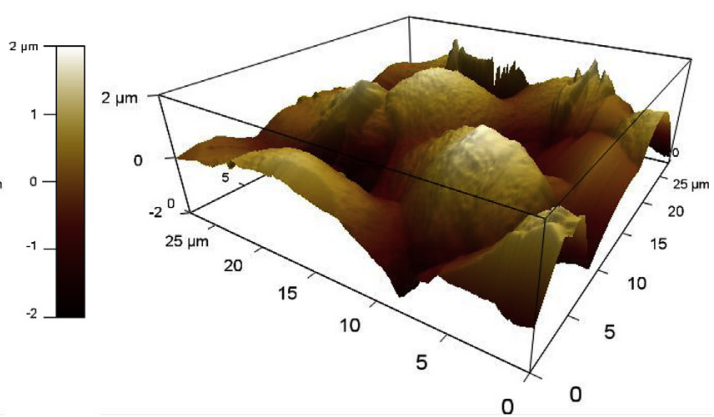

d

$\theta=133.1 \pm 2.6^{\circ}$

Fig. 7. AFM images showing the topography of (a) SGO/PVDF membrane, and (b) PVDF membrane. Water contact angle of membrane samples (c) SGO/PVDF CEM, (d) PVDF. 
Table 1

Membrane wettability parameters.

\begin{tabular}{llll}
\hline & Water contact angle & Water uptake & Swelling ratio \\
\hline SGO/PVDF & $80.8 \pm 1.5^{\circ}$ & $270.94 \pm 0.07 \%$ & $2.71 \pm 0.01 \%$ \\
Plain PVDF & $133.1 \pm 2.6^{\circ}$ & $2.65 \pm 0.01 \%$ & $2.67 \pm 0.01 \%$ \\
\hline
\end{tabular}

Table 2

Electrochemical properties of SGO/PVDF membrane.

\begin{tabular}{ll}
\hline Electrochemical property & SGO/PVDF membrane \\
\hline IEC $[\mathrm{meq} / \mathrm{g}]$ & $0.63 \pm 0.08$ \\
Transport number & $0.92 \pm 0.07$ \\
Permselectivity $^{\mathrm{a}}$ & $0.95 \pm 0.04$ \\
${\text { Area resistance }\left[\Omega \mathrm{cm}^{2}\right]}^{2.8 \pm 0.2}$ \\
\hline
\end{tabular}

a Obtained from chronopotentiometry.

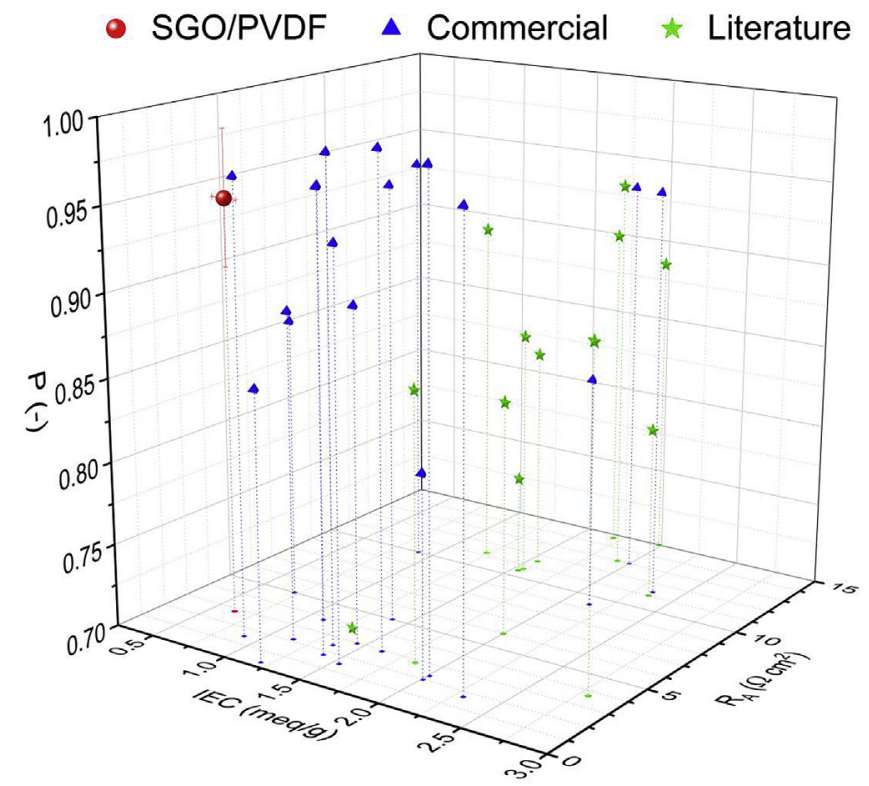

Fig. 8. Comparison of the ion exchange capacity (IEC), permselectivity (P) and area resistance $\left(\mathrm{R}_{\mathrm{A}}\right)$ of SGO/PVDF with commercial CEMs and other heterogeneous CEMs reported in the literature [59].

response analyzer, was used to perform the EIS experiments according to procedures found in the literature [57]. The measurements were conducted using a $0.1 \mathrm{~mA}$ amplitude AC signal at 50 different frequencies ranging from $1 \mathrm{mHz}$ to $1 \mathrm{kHz}$. Equivalent circuit fitting was used to determine the resistance of the membrane in solution $\left(R_{m+s o l}\right)$ according to a reported method (Fig. 4) [58]. The membrane area resistance was obtained using Eq. (5):

$R_{\mathrm{A}}=\left(R_{\mathrm{m}+\mathrm{sol}}-R_{\mathrm{sol}}\right) \cdot A$

where $R_{\mathrm{A}}$ is the membrane area resistance, $R_{\mathrm{m}+\text { sol }}$ is the resistance of the membrane in the solution, $R_{\mathrm{sol}}$ is the resistance of the empty cell, and $A$ is the membrane area. The measurement was triplicated with different membrane pieces.

\section{Results and discussion}

\subsection{Membrane structure and composition}

SEM micrographs of the SGO/PVDF and plain PVDF membrane samples are shown in Fig. 5. Top surface and cross-section images reveal a marked difference in morphology of the two membrane samples. The SGO sheets can be observed on the SGO/PVDF membrane surface
(Fig. 5a). The cross-sectional image of the SGO/PVDF membrane (Fig. 5b) appears to have a densely-stacked sheet structure, whereas the plain PVDF membrane possesses a typical polymeric porous structure. The plain PVDF membrane is a homogeneous membrane and has no SGO, while the SGO/PVDF is a heterogeneous membrane with almost $50 \%$ of its composition as SGO nanosheets. Hence, there are obvious differences in the morphologies of the membranes. The thickness of the SGO/PVDF membrane was determined to be $29.72 \pm 0.81 \mu \mathrm{m}$, while that of the PVDF membrane was $24.08 \pm 0.47 \mu \mathrm{m}$. The sheet-like structure of the SGO/PVDF membrane can be attributed to the SGO additive. The SGO appears to be well distributed in the membrane as depicted by the consistency in membrane morphology in both top and cross-section micrographs. Additive agglomeration is undesirable in nanocomposite membranes. It can result in membrane brittleness and also restricts access to ion exchange groups. From the SEM micrograph of the SGO/PVDF membrane, it can be concluded there was minimal agglomeration of the SGO additive materials in the membrane matrix. Decline in stability is also common with nanocomposite membranes with high additive loadings. However, despite the high SGO loading and low polymer content, the SGO/PVDF membrane remained intact after handling. This is because the SGO additives not only have a 2Dsheet structure but also are soft and flexible, both properties are favorable for blending with the polymeric components and forming nanocomposite membranes with uniform consistency. In addition, the mold-casting with dry thermal inversion technique, used to fabricate the membranes, also contributed positively to the good quality of the composite membrane. Since SGO carries sulfonic groups, the presence of sulfur in the SGO/PVDF membrane can be detected by EDS elemental mapping (Fig. 6). The added SGO is well distributed spatially across the entire membrane body. In addition, with aggregates showing higher concentration of $S$ in the EDS map probably due to the folding of GO sheets (Fig. 6e and k). This further confirms SGO can successfully introduce the sulfonic groups into the PVDF matrix to form SGO/PVDF ion exchange membrane.

\subsection{Membrane surface roughness and wettability}

The AFM topography images of the membranes are shown in Fig. 7a and $\mathrm{b}$. The RMS roughness of the PVDF membranes was $878 \mathrm{~nm}$, while the RMS roughness of the SGO/PVDF membrane was $193 \mathrm{~nm}$. This suggests the PVDF membrane has a rougher surface than the SGO/ PVDF membrane, which is consistent with the morphology images from the SEM.

Water contact angle (Table 1 and Fig. $7 \mathrm{c}$ and d) and water uptake measurements (Table 1 ) were performed to assess the wettability/hydrophilicity of the membranes. Results showed the water contact angle of the SGO/PVDF membrane to be less than that of the PVDF membrane. In addition, the water uptake of the SGO/PVDF membrane was much higher than that of the PVDF membrane. The water contact angle and water uptake results revealed the SGO/PVDF membrane to be more hydrophilic, thus making it suitable for electromembrane desalination applications. The increased hydrophilicity was due to the presence of sulfonic groups from the SGO additive and also the hydrophilic nature of the GO base material. Although a significantly high water uptake of $270.94 \pm 0.07 \%$ was achieved by the nanocomposite CEM, which provided a good basis for its robust permselectivity, the swelling ratio of the SGO/PVDF membrane was essentially the same as of the plain PVDF membrane at around $2.7 \%$ (Table 1). The low swelling ratio indicated a reasonable stability of the nanocomposite CEM under wet conditions.

The above SEM image and membrane wettability analysis suggest that the SGO/PVDF membrane had a densely packed structure and offers a more hydrophilic surface than the plain PVDF polymeric membrane. These desirable features of the SGO/PVDF membrane are necessary in order to achieve good ion exchange performance. 

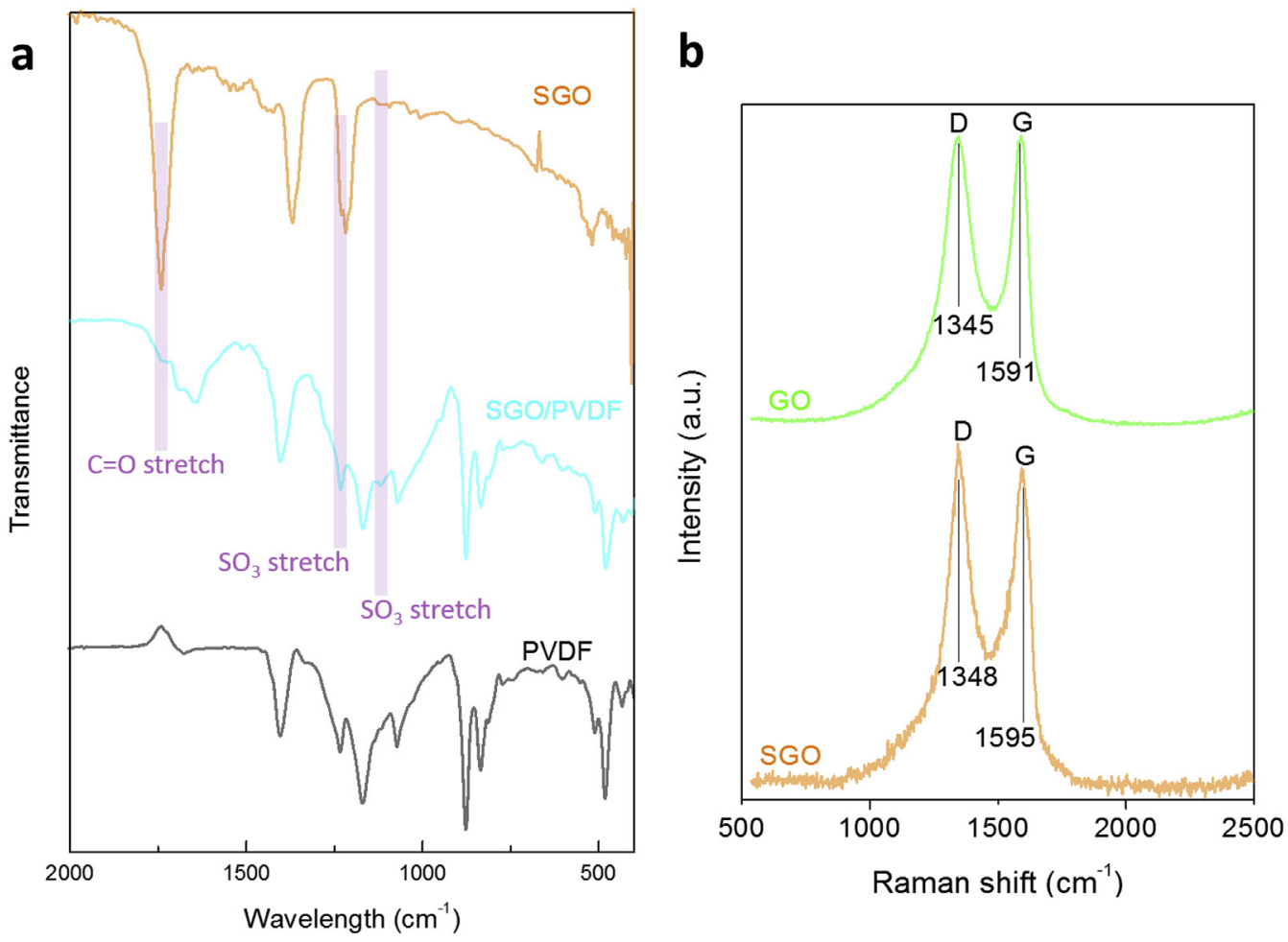

Fig. 9. (a) FTIR characterization of SGO, SGO/PVDF and PVDF. (b) Raman characterization of GO and SGO.

\subsection{Electrochemical properties}

Electrochemical properties of IEMs are critical parameters which determine to a great degree the performance of IEMs in electromembrane desalination processes. The electrochemical properties of the SGO/PVDF membrane are shown in Table 2.

The IEC is a measure of the ion exchange sites present in an IEM, and is a critical property which influences virtually all other IEM properties. In the SGO/PVDF nanocomposite membrane the IEC corresponds to the amount of sulfonic groups present for ion exchange. The IEC was determined to be $0.63 \pm 0.08 \mathrm{meq} / \mathrm{g}$, which was lower than the IEC of top commercial CEMs but comparable with IEC values of: CSMCRI HGC heterogeneous CEM (0.67-0.77 meq/g) [59]; Nafion-117 (0.80 meq/g) [60]; and some fabricated CEMs reported in literature (roughly $0.70 \mathrm{meq} / \mathrm{g}$ ) $[60,61]$.

The permselectivity and the area resistance of the SGO/PVDF nanocomposite membrane were found to be $0.95 \pm 0.04$ and $2.8 \pm 0.2 \Omega \mathrm{cm}^{2}$, respectively. To put these values in context, the electrochemical properties were compared in Fig. 8 to commercial CEMs and other heterogeneous CEMs reported in the literature [59]. From an application point of view, an ideal CEM would have a permselectivity of 1 and area resistance of 0 . As shown in the figure, SGO/PVDF outperformed the other heterogeneous CEMs from the literature in terms of both permselectivity and area resistance. The electrochemical properties of SGO/PVDF were comparable to commercial CEMs despite its lower IEC. Fig. 8 also showed that while it was generally accepted that higher IEC results in lower area resistance, no direct correlation can be observed in the 0.5-3 meq/g IEC range among the depicted CEMs. This meant that membrane properties other than IEC also played a role in the area resistance. IEMs are usually crosslinked to prevent excessive membrane swelling [55]. Membrane swelling is undesirable because it results in membrane instability which then leads to poor membrane performance. Cross-linking is effective in reducing membrane swelling, but it also leads to increases in area resistance. For the SGO/PVDF membrane, cross-linking was not required due to its low swelling ratio. The absence of cross-linking may explain the low area resistance observed in this work. Moreover, the high water uptake also contributed to the notable area resistance.

\subsection{Characterization by FTIR and Raman spectroscopy}

Fig. 9a showed the FTIR spectra for SGO, SGO/PVDF and PVDF. The vibration peak at $1736 \mathrm{~cm}^{-1}$ corresponds to $\mathrm{C}=\mathrm{O}$ stretching vibration (from the graphene oxide base material). The successful incorporation of PSS was demonstrated by the appearance of vibration peaks at $1228 \mathrm{~cm}^{-1}$ and $1157 \mathrm{~cm}^{-1}$, which correspond to $\mathrm{SO}_{3}$ stretching. The aforementioned $\mathrm{C}=\mathrm{O}$ stretching peak and $\mathrm{SO}_{3}$ stretching peaks were also present in the spectra of the SGO/PVDF membrane, indicating the successful incorporation of SGO into the membrane.

Raman spectra of GO and SGO are shown in Fig. 9b, where the typical D and G bands for GO-based nanomaterials are present in both spectra. The $\mathrm{D}$ band was related to the density of disorder sites, whereas the $\mathrm{G}$ band reflected the conjugated structure of the $\mathrm{sp}^{2}$ carbon framework $[62,63]$. The ratios of intensity of $\mathrm{D}$ band to $\mathrm{G}$ band were 1.000 and 1.002 for GO and SGO respectively. The similar D and G ratio confirms no significant change in the oxygen functional groups at the $\mathrm{GO}$, which is only slightly affected by incorporation of sulfonic groups via PSS on the GO nanosheets.

\section{Conclusion}

In this study, we reported the preparation of a graphene oxide nanocomposite $\mathrm{CEM}$, in which the ion exchange groups $\left(-\mathrm{SO}_{3}{ }^{-}\right)$were provided by the sulfonic group containing graphene oxide nanocomposite (SGO) with $45 \mathrm{wt} \%$ loading. SGO was prepared via co-adsorption of graphene oxide (GO) with an agent derived from 3,4-dihydroxy-L-phenylalanine (L-DOPA) and poly(sodium 4styrenesulfonate) (PSS). Successful incorporation of sulfonic groups to the GO nanocomposite was demonstrated by FTIR spectroscopy. Morphological, wettability, and electrochemical characterization methods were used to assess the impact of the SGO additive on the membranes. AFM, SEM and EDS characterization showed the 
distribution of the SGO additives across the entire membrane matrix. Water contact angle $\left(80.8 \pm 1.5^{\circ}\right)$ and water uptake $(270.94 \pm 0.07 \%)$ demonstrated the high hydrophilicity of the membrane, which is suitable for water treatment applications. The nanocomposite CEM was found to possess good IEC $(0.63 \pm 0.08 \mathrm{meq} / \mathrm{g})$, permselectivity $(0.95 \pm 0.04)$, and area resistance $\left(2.8 \pm 0.2 \Omega \mathrm{cm}^{2}\right)$. The permselectivity, and area resistance were much better than commercial CEM (Ralex). This research demonstrated that the nanocomposite CEM prepared by electrostatically-coupling of PSS/L-DOPA/ GO/PVDF approach shows good potential for use in electromembrane desalination applications.

\section{Conflicts of interest}

The authors declare no conflict of interest.

\section{Acknowledgement}

This manucript is part of the collaborative project between Masdar Institute-Khalifa University and University of Manchester (SMG2016000001). The authors acknowledge the financial support of Khalifa University, Abu Dhabi, UAE, and the University of Manchester. The authors would also like to thank Habeebllah Oladipo and Tuza Olukan for their help with AFM characterizations; Mahendra Kumar and Moza Al Humaidi for helping with water contact angle measurements; and Cyril Aubry and Hammed Younes for assisting with Raman spectroscopy.

\section{References}

[1] S. Loutatidou, M.O. Mavukkandy, S. Chakraborty, H.A. Arafat, Chapter 1 - introduction: what is sustainable desalination? in: H.A. Arafat (Ed.), Desalination Sustainability, Elsevier, 2017, pp. 1-30.

[2] H. Strathmann, Electrodialysis, a mature technology with a multitude of new applications, Desalination 264 (2010) 268-288.

[3] Y. Tanaka, Ion-exchange membrane electrodialysis for saline water desalination and its application to seawater concentration, Ind. Eng. Chem. Res. 50 (2011) 7494-7503.

[4] Y. Tanaka, Ion-exchange membrane electrodialysis program and its application to multi-stage continuous saline water desalination, Desalination 301 (2012) 10-25.

[5] A. Campione, L. Gurreri, M. Ciofalo, G. Micale, A. Tamburini, A. Cipollina, Electrodialysis for water desalination: a critical assessment of recent developments on process fundamentals, models and applications, Desalination 434 (2018) $121-160$.

[6] H. Strathmann, Ion-exchange membrane processes in water treatment, in: I.C. Escobar, A.I. Schäfer (Eds.), Sustainability Science and Engineering, Elsevier, 2010, pp. 141-199.

[7] H. Strathmann, Introduction to Membrane Science and Technology, Wiley-VCH Weinheim, Germany, 2013

[8] A. Moura Bernardes, M.A.S. Rodrigues, Electrodialysis in water treatment, in: A. Moura Bernardes, M.A. Siqueira Rodrigues, J. Zoppas Ferreira (Eds.), Electrodialysis and Water Reuse: Novel Approaches, Springer Berlin Heidelberg, Berlin, Heidelberg, 2014, pp. 63-75.

[9] H. Li, L. Zou, Ion-exchange membrane capacitive deionization: a new strategy for brackish water desalination, Desalination 275 (2011) 62-66.

[10] P.M. Biesheuvel, A. Van der Wal, Membrane capacitive deionization, J. Membr. Sci. 346 (2010) 256-262.

[11] S. Porada, R. Zhao, A. van der Wal, V. Presser, P.M. Biesheuvel, Review on the science and technology of water desalination by capacitive deionization, Prog. Mater. Sci. 58 (2013) 1388-1442.

[12] F.A. AlMarzooqi, A.A. Al Ghaferi, I. Saadat, N. Hilal, Application of Capacitive Deionisation in water desalination: a review, Desalination 342 (2014) 3-15.

[13] M.E. Suss, S. Porada, X. Sun, P.M. Biesheuvel, J. Yoon, V. Presser, Water desalination via capacitive deionization: what is it and what can we expect from it? Energy Environ. Sci. 8 (2015) 2296-2319.

[14] M. Mulder, Basic Principles of Membrane Technology, second ed., Kluwer Academic Publishers, The Netherlands, 2003.

[15] Y. Tanaka, Ion Exchange Membranes: Fundamentals and Applications, second ed., Elsevier, Amsterdam, 2015.

[16] T. Sata, Ion Exchange Membranes: Preparation, Characterization, Modification and Application, The Royal Society of chemistry, Cambridge, UK, 2004.

[17] T. Xu, Ion exchange membranes: state of their development and perspective, J. Membr. Sci. 263 (2005) 1-29.

[18] M.C. Martí-Calatayud, D.C. Buzzi, M. García-Gabaldón, A.M. Bernardes, J.A.S. Tenório, V. Pérez-Herranz, Ion transport through homogeneous and heterogeneous ion-exchange membranes in single salt and multicomponent electrolyte solutions, J. Membr. Sci. 466 (2014) 45-57.

[19] A. Alabi, A. AlHajaj, L. Cseri, G. Szekely, P. Budd, L. Zou, Review of nanomaterialsassisted ion exchange membranes for electromembrane desalination, npj Clean. Water 1 (2018) 10.

[20] S.M. Hosseini, S.S. Madaeni, A.R. Khodabakhshi, Preparation and characterization of PC/SBR heterogeneous cation exchange membrane filled with carbon nanotubes, J. Membr. Sci. 362 (2010) 550-559.

[21] C. Klaysom, S.-H. Moon, B.P. Ladewig, G.M. Lu, L. Wang, The influence of inorganic filler particle size on composite ion-exchange membranes for desalination, J. Phys. Chem. C 115 (2011) 15124-15132.

[22] L. Cseri, J. Baugh, A. Alabi, A. AlHajaj, L. Zou, R.A.W. Dryfe, P.M. Budd, G. Szekely, Graphene oxide-polybenzimidazolium nanocomposite anion exchange membranes for electrodialysis, J. Mater. Chem. 6 (2018) 24728-24739.

[23] F. Perreault, A. Fonseca de Faria, M. Elimelech, Environmental applications of graphene-based nanomaterials, Chem. Soc. Rev. 44 (2015) 5861-5896.

[24] S. Banerjee, J.H. Lee, T. Kuila, N.H. Kim, Synthesis of graphene-based polymeric nanocomposites, in: Y. Dong, R. Umer, A. Kin Tak Lau (Eds.), Fillers and Reinforcements for Advanced Nanocomposites, Woodhead Publishing, UK, 2015 pp. 133-156.

[25] J. Du, H.M. Cheng, The fabrication, properties, and uses of graphene/polymer composites, Macromol. Chem. Phys. 213 (2012) 1060-1077.

[26] J.R. Potts, D.R. Dreyer, C.W. Bielawski, R.S. Ruoff, Graphene-based polymer nanocomposites, Polymer 52 (2011) 5-25.

[27] T. Kuilla, S. Bhadra, D. Yao, N.H. Kim, S. Bose, J.H. Lee, Recent advances in graphene based polymer composites, Prog. Polym. Sci. 35 (2010) 1350-1375.

[28] B.M. Yoo, H.J. Shin, H.W. Yoon, H.B. Park, Graphene and graphene oxide and their uses in barrier polymers, J. Appl. Polym. Sci. 131 (2014).

[29] S. Daer, J. Kharraz, A. Giwa, S.W. Hasan, Recent applications of nanomaterials in water desalination: a critical review and future opportunities, Desalination 367 (2015) 37-48.

[30] J.I. Paredes, S. Villar-Rodil, A. Martínez-Alonso, J.M.D. Tascon, Graphene oxide dispersions in organic solvents, Langmuir 24 (2008) 10560-10564.

[31] R. Atif, F. Inam, Reasons and remedies for the agglomeration of multilayered graphene and carbon nanotubes in polymers, Beilstein J. Nanotechnol. 7 (2016) 1174-1196.

[32] D.G. Papageorgiou, I.A. Kinloch, R.J. Young, Mechanical properties of graphene and graphene-based nanocomposites, Prog. Mater. Sci. 90 (2017) 75-127.

[33] J. Yin, B. Deng, Polymer-matrix nanocomposite membranes for water treatment, J. Membr. Sci. 479 (2015) 256-275.

[34] F. Hussain, M. Hojjati, M. Okamoto, R.E. Gorga, Polymer-matrix nanocomposites, processing, manufacturing, and application: an overview, J. Compos. Mater. 40 (2006) 1511-1575.

[35] S. Zheng, Q. Tu, J.J. Urban, S. Li, B. Mi, Swelling of graphene oxide membranes in aqueous solution: characterization of interlayer spacing and insight into water transport mechanisms, ACS Nano 11 (2017) 6440-6450.

[36] S. Gahlot, P.P. Sharma, H. Gupta, V. Kulshrestha, P.K. Jha, Preparation of graphene oxide nano-composite ion-exchange membranes for desalination application, RSC Adv. 4 (2014) 24662-24670.

[37] Y. He, C. Tong, L. Geng, L. Liu, C. Lü, Enhanced performance of the sulfonated polyimide proton exchange membranes by graphene oxide: size effect of graphene oxide, J. Membr. Sci. 458 (2014) 36-46.

[38] L. Liu, C. Tong, Y. He, Y. Zhao, C. Lü, Enhanced properties of quaternized graphenes reinforced polysulfone based composite anion exchange membranes for alkaline fuel cell, J. Membr. Sci. 487 (2015) 99-108.

[39] W.-H. Pan, S.J. Lue, C.-M. Chang, Y.-L. Liu, Alkali doped polyvinyl alcohol/multiwalled carbon nano-tube electrolyte for direct methanol alkaline fuel cell, J. Membr. Sci. 376 (2011) 225-232.

[40] Y.-S. Ye, M.-Y. Cheng, X.-L. Xie, J. Rick, Y.-J. Huang, F.-C. Chang, B.-J. Hwang, Alkali doped polyvinyl alcohol/graphene electrolyte for direct methanol alkaline fuel cells, J. Power Sources 239 (2013) 424-432.

[41] J.-M. Yang, S.-A. Wang, Preparation of graphene-based poly(vinyl alcohol)/chitosan nanocomposites membrane for alkaline solid electrolytes membrane, J. Membr. Sci. 477 (2015) 49-57.

[42] S.M. Hosseini, P. Koranian, A. Gholami, S.S. Madaeni, A.R. Moghadassi, P. Sakinejad, A.R. Khodabakhshi, Fabrication of mixed matrix heterogeneous ion exchange membrane by multiwalled carbon nanotubes: electrochemical characterization and transport properties of mono and bivalent cations, Desalination 329 (2013) 62-67.

[43] A. Zendehnam, S. Mokhtari, S.M. Hosseini, M. Rabieyan, Fabrication of novel heterogeneous cation exchange membrane by use of synthesized carbon nanotubesco-copper nanolayer composite nanoparticles: characterization, performance in desalination, Desalination 347 (2014) 86-93.

[44] S.M. Hosseini, F. Jeddi, M. Nemati, S.S. Madaeni, A.R. Moghadassi, Electrodialysis heterogeneous anion exchange membrane modified by PANI/MWCNT composite nanoparticles: preparation, characterization and ionic transport property in desalination, Desalination 341 (2014) 107-114.

[45] Y. Zhao, Y. Li, S. Yuan, J. Zhu, S. Houtmeyers, J. Li, R. Dewil, C. Gao, B. Van der Bruggen, A chemically assembled anion exchange membrane surface for monovalent anion selectivity and fouling reduction, J. Mater. Chem. 7 (2019) 6348-6356.

[46] A. Nguyen, S. Azari, L. Zou, Coating zwitterionic amino acid l-DOPA to increase fouling resistance of forward osmosis membrane, Desalination 312 (2013) 82-87.

[47] J. Choi, S. Yang, N.-J. Jeong, H. Kim, W.-S. Kim, Fabrication of an anion-exchange membrane by pore-filling using catechol-1,4-diazabicyclo-[2,2,2]octane coating and its application to reverse electrodialysis, Langmuir 34 (2018) 10837-10846.

[48] S. Moulay, Dopa/catechol-tethered polymers: bioadhesives and biomimetic 
adhesive materials, Polym. Rev. 54 (2014) 436-513.

[49] H. Lee, S.M. Dellatore, W.M. Miller, P.B. Messersmith, Mussel-inspired surface chemistry for multifunctional coatings, Science 318 (2007) 426-430.

[50] J.H. Ryu, P.B. Messersmith, H. Lee, Polydopamine surface chemistry: a decade of discovery, ACS Appl. Mater. Interfaces 10 (2018) 7523-7540.

[51] L. Yu, X. Liu, W. Yuan, L.J. Brown, D. Wang, Confined flocculation of ionic pollutants by poly(L-dopa)-based polyelectrolyte complexes in hydrogel beads for threedimensional, quantitative, efficient water decontamination, Langmuir 31 (2015) 6351-6366.

[52] S. Park, R.S. Ruoff, Chemical methods for the production of graphenes, Nat. Nanotechnol. 4 (2009) 217.

[53] R.K. Joshi, P. Carbone, F.C. Wang, V.G. Kravets, Y. Su, I.V. Grigorieva, H.A. Wu, A.K. Geim, R.R. Nair, Precise and ultrafast molecular sieving through graphene oxide membranes, Science 343 (2014) 752.

[54] Q. Yang, Y. Su, C. Chi, C.T. Cherian, K. Huang, V.G. Kravets, F.C. Wang, J.C. Zhang, A. Pratt, A.N. Grigorenko, F. Guinea, A.K. Geim, R.R. Nair, Ultrathin graphenebased membrane with precise molecular sieving and ultrafast solvent permeation, Nat. Mater. 16 (2017) 1198.

[55] H. Strathmann, Ion-exchange Membrane Separation Processes, first ed., Elsevier, Amsterdam, The Netherlands, 2004.

[56] N. Pismenskaia, P. Sistat, P. Huguet, V. Nikonenko, G. Pourcelly, Chronopotentiometry applied to the study of ion transfer through anion exchange membranes, J. Membr. Sci. 228 (2004) 65-76.

[57] S. Abdu, M.-C. Martí-Calatayud, J.E. Wong, M. García-Gabaldón, M. Wessling, Layer-by-Layer modification of cation exchange membranes controls ion selectivity and water splitting, ACS Appl. Mater. Interfaces 6 (2014) 1843-1854.

[58] J.-S. Park, J.-H. Choi, K.-H. Yeon, S.-H. Moon, An approach to fouling characterization of an ion-exchange membrane using current-voltage relation and electrica impedance spectroscopy, J. Colloid Interface Sci. 294 (2006) 129-138.

[59] D. Energy \& Environmental ScienceAriono, Subagjo Khoiruddin, I.G. Wenten, Heterogeneous structure and its effect on properties and electrochemical behavior of ion-exchange membrane, Mater. Res. Express 4 (2017) 024006.

[60] K. Dutta, S. Das, P.P. Kundu, Effect of the presence of partially sulfonated polyaniline on the proton and methanol transport behavior of partially sulfonated PVDF membrane, Polym. J. 48 (2015) 301.

[61] H. Farrokhzad, T. Kikhavani, F. Monnaie, S.N. Ashrafizadeh, G. Koeckelberghs, T. Van Gerven, B. Van der Bruggen, Novel composite cation exchange films based on sulfonated PVDF for electromembrane separations, J. Membr. Sci. 474 (2015) $167-174$.

[62] I.K. Moon, J. Lee, R.S. Ruoff, H. Lee, Reduced graphene oxide by chemical graphitization, Nat. Commun. 1 (2010) 73.

[63] G. Eda, G. Fanchini, M. Chhowalla, Large-area ultrathin films of reduced graphene oxide as a transparent and flexible electronic material, Nat. Nanotechnol. 3 (2008) 270. 